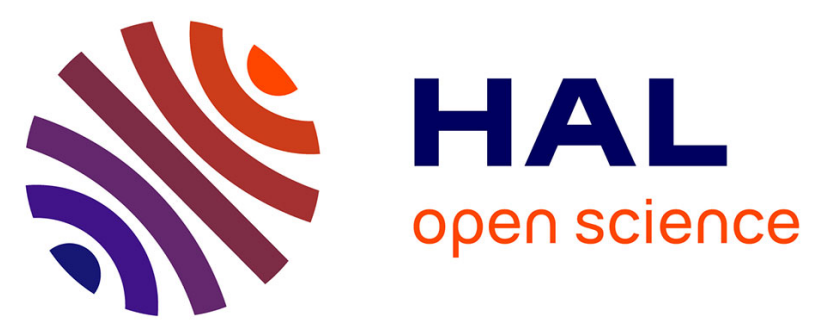

\title{
Virtual reexamination of a plesiosaurian specimen (Reptilia, Plesiosauria) from the Late Cretaceous (Turonian) of Goulmima, Morocco, thanks to computed tomography
}

Rémi Allemand, Nathalie Bardet, Alexandra Houssaye, Peggy Vincent

\section{To cite this version:}

Rémi Allemand, Nathalie Bardet, Alexandra Houssaye, Peggy Vincent. Virtual reexamination of a plesiosaurian specimen (Reptilia, Plesiosauria) from the Late Cretaceous (Turonian) of Goulmima, Morocco, thanks to computed tomography. Journal of Vertebrate Paleontology, 2017, 37 (3), pp.e1325894. 10.1080/02724634.2017.1325894 . hal-01681238

\section{HAL Id: hal-01681238 \\ https: / hal.sorbonne-universite.fr/hal-01681238}

Submitted on 6 Feb 2018

HAL is a multi-disciplinary open access archive for the deposit and dissemination of scientific research documents, whether they are published or not. The documents may come from teaching and research institutions in France or abroad, or from public or private research centers.
L'archive ouverte pluridisciplinaire HAL, est destinée au dépôt et à la diffusion de documents scientifiques de niveau recherche, publiés ou non, émanant des établissements d'enseignement et de recherche français ou étrangers, des laboratoires publics ou privés. 
Virtual re-examination of a plesiosaurian specimen (Reptilia, Plesiosauria) from the Late

Cretaceous (Turonian) of Goulmima (Southern Morocco) thanks to computed tomography RÉMI ALLEMAND, ${ }^{*}, 1,2$ NATHALIE BARDET,${ }^{1}$ ALEXANDRA HOUSSAYE,${ }^{2}$ and PEGGY VINCENT ${ }^{1}$

${ }^{1}$ Centre de Recherches sur la Paléobiodiversité et les Paléoenvironnements, CR2P-UMR 7207, CNRS, MNHN, UPMC, Sorbonne Universités, 57 rue Cuvier, CP38, F-75005, Paris, France, remi.allemand@edu.mnhn.fr, nathalie.bardet@mnhn.fr, peggy.vincent@mnhn.fr;

${ }^{2}$ UMR 7179, CNRS, MNHN, Département Ecologie et Gestion de la Biodiversité, 57 rue Cuvier, CP55, F-75005, Paris, France, alexandra.houssaye@mnhn.fr RH:ALLEMAND ET AL._-VIRTUAL RECONSTRUCTION OF A PLESIOSAURIAN SPECIMEN

\footnotetext{
* Corresponding author
} 
ABSTRACT - Turonian deposits of the Goulmima area, Er-Rachidia Province in Southern Morocco, have yielded a diverse marine vertebrate fauna, including chondrichthyans, bony fishes and large marine reptiles such as plesiosaurians, mosasauroids and turtles. These fossils are included in ovoid calcareous nodules that are difficult to prepare. Moreover, bones may be partially or totally dissolved, making their study difficult. Using computed tomography, we have reconstructed the entire skull anatomy of SMNS 81783, one of the rare plesiosaurian specimens found in this locality and more generally in Africa. The digital 3D reconstruction of the skull and mandible offers for the first time the possibility to exhaustively describe this specimen. The new anatomical characters recorded confirm that the SMNS 81783 belongs to Elasmosauridae on the basis of: (1) slender triangular skull; (2) a beak index equal to $42 \%$; (3) temporal fossa estimated to occupy about $40 \%$ of the skull length; (4) long process of the premaxillae extending posteriorly to meet the parietal above the orbit and separating the frontals; (5) margin of the temporal fenestra lacking obvious contribution from the frontal. A preliminary phylogenetic analysis confirms its elasmosaurid affinity. The relationships between SMNS 81783, Libonectes atlasense and Libonectes morgani, as well as the presence of stapes and pineal foramen are discussed.

\section{INTRODUCTION}

Plesiosaurians are extinct predatory marine reptiles that represent one of the longestranging groups of Mesozoic marine reptiles, ranging stratigraphically from the Late Triassic to the latest Cretaceous (e.g., Benson et al., 2012; Vincent et al., 2013). Plesiosaurians became extinct during the Cretaceous-Paleogene biological crisis (Vincent et al., 2011; Gasparini et al., 2003a). However, during the Late Cretaceous, they had a worldwide distribution, including high-latitude seas surrounding Antarctica (Gasparini et al., 2003b; Novas et al., 
2015). The fossil record of plesiosaurians is scarcer in Africa than in other continents (Vincent et al., 2011, 2013). Up to now, six valid taxa have been described in this continent: Leptocleidus capensis Andrews, 1911 from the Valanginian (Early Cretaceous) of South Africa (Andrews, 1911; Cruickshank, 1997), Thililua longicollis Bardet et al., 2003a, Manemergus anguirostris Buchy et al., 2005, Libonectes atlasense Buchy, 2005, and Brachauchenius lucasi Williston, 1903 all four from the Turonian (Late Cretaceous) of Morocco (Bardet et al., 2003a; Buchy, 2005; Buchy et al., 2005; Angst and Bardet, 2015), Zarafasaura oceanis Vincent et al., 2011 and Cardiocorax mukulu Araújo et al., 2015 from the Maastrichtian (latest Cretaceous) of Morocco (Vincent et al., 2011, Lomax and Wahl, 2013) and Angola (Araújo et al., 2015). Very fragmentary remains indeterminable at an infrafamilial level were also described from the Maastrichtian of Morocco, Egypt and Angola (e.g., Stromer, 1935; see Vincent et al., 2013 for details).

In Morocco, the Goulmima area is in the southern slope of the High Atlas (see Fig. 1A) (Bardet et al., 2003a, 2003b; 2008). The latter exposes several fossiliferous localities of early Late Cretaceous (Turonian) age that have yielded a diverse marine fauna including ammonites, chondrichthyans (Underwood et al., 2009), bony fishes (Cavin, 1995, 1997, 1999, 2001; Cavin et al., 2001, 2010) and large marine reptiles, such as a turtle, the basal mosasauroid Tethysaurus nopcsai Bardet et al., 2003b (Bardet et al., 2003b, 2008) and four plesiosaurian taxa: Thililua longicolis, Manemergus anguirostris, Libonectes atlasense, and Brachauchenius lucasi (Bardet et al., 2003a; Buchy, 2005; Buchy et al., 2005; Angst and Bardet, 2015). According to Cavin et al. (2010), the vertebrate fossils are contained in ovoid, early diagenetic, calcareous nodules up to $1 \mathrm{~m}$ in size. The fossiliferous nodules contain skeletal remains, mainly skulls and vertebral elements, and the marine reptile specimens are sometimes preserved in several distinct nodules (Cavin et al., 2010). Although fossils from this assemblage can sometimes be chemically prepared by dissolving the matrix with formic 
acid, in many cases the nodule core is composed of siliceous material that prevents complete preparation of the specimens (Cavin et al., 2010). Moreover, fossilized bones in the nodules are often completely dissolved, making their extraction from the host rock and their study difficult or impossible. This particular preservation can often prevent a complete access to the fossil anatomy and the use of computed microtomography represents a suitable solution to circumvent these technical issues. Here, we used microtomography on a plesiosaurian specimen (SMNS 81783) from this locality. This specimen, poorly preserved in an incompletely prepared nodule (Fig. 1B), was previously referred to Libonectes atlasense (Buchy, 2005). This technique reveals details of anatomy that are not otherwise directly observable.

Institutional Abbreviations-MNHN, Muséum National d'Histoire Naturelle, Paris, France; SMNS, Staatliches Museum für Naturkunde, Stuttgart, Germany; SMU SMP, Shuler Museum of Paleontology, Southern Methodist University, Dallas, U.S.A.

\section{GEOGRAPHICAL AND STRATGRAPHICAL CONTEXT}

According to Buchy (2005:6), the specimen comes from 'some kilometers around Goulmima' in Southern Morocco (Fig. 1), as is the case for the type specimen of Libonectes atlasense and Manemergus anguirostris (Buchy, 2005; Buchy et al., 2005). Although their exact location remains unknown, the calcareous matrix surrounding these specimens is consistent with the vertebrate-bearing nodules known from the early Turonian of the Goulmima area (Cavin 1995, 1997, 1999, 2001; Cavin et al., 2001; Bardet et al., 2003a, 2003b; Buchy, 2005; Buchy et al., 2005). These nodules are concentrated near the top of a Cenomanian-Turonian calcareous succession, in Unit 4 of Ferrandini et al. (1985), previously considered as early Turonian in age based on the ammonite assemblage (mainly Mammites) 
(Bardet et al., 2003a, 2003b, 2008). It was later reappraised as Unit T2a of the Akrabou

Formation, middle Turonian in age, by Ettachfini and Andreu (2004). The Goulmima area was the center of a basin exemplifying large subsidence during the Cenomanian-Turonian transgression. It corresponds to an open marine carbonate platform with influences essentially from the Tethys but also from the Central Atlantic (Cavin et al., 2001; Ettachfini and Andreu, 2004; Bardet et al., 2008). The Goulmima deposits surrounding the nodules correspond to marine limestones deposited in dysoxic conditions (Lebedel et al., 2013).

\section{MATERIAL AND METHODS}

The specimen is currently housed in the SMNS under collection number SMNS 81783. It is preserved in a nodule about $40 \mathrm{~cm}$ long, up to $11 \mathrm{~cm}$ wide and $13 \mathrm{~cm}$ high (Fig. 2A, B), which encompasses a skull with the mandible in occlusion and the atlas-axis complex. The specimen is incompletely prepared. Its anterior half shows bones incompletely dissolved and exposed, surrounded by a light beige matrix (Fig. 2A, B). The posterior half of the fossil is still embedded in the matrix and thus not observable.

SMNS 81783 was scanned at the AST-RX platform of the MNHN (Paris) using a GEphoenix|Xray|v|tome|x L240 with a voxel size of $134 \mu \mathrm{m}$ (voltage: $230 \mathrm{kV}$, intensity: 500 $\mu \mathrm{A})$. A virtual three-dimensional reconstruction of the skull was then performed at the Palaeontology Imaging Unit of the MNHN Département Histoire de la Terre/UMR 7207 CR2P CNRS/MNHN/UPMC using the MIMICS (Materialise Interactive Medical Image Control System) Innovation Suite software (Materialise ${ }^{\circledR}$, release 18). During segmentation work, bony elements appeared generally with darker grayscale values than the matrix (Fig. 2) due to the different X-ray absorption coefficients. However, no unique threshold value could accurately describe the boundary between bone and the matrix. The reconstruction was thus 
realized with the multiple 2D cross-sectional slices edit tool of MIMICS and interpolation between selections on non-contiguous slices. The shape of some bones that appeared completely dissolved at the surface of the nodule has been reconstructed using their natural cast encased in the matrix. This was the case for the mandible, for which only the cast of the medial margin is preserved (Fig. 2C) so that the lateral margin was reconstructed by an approximate extension of its contour (see Fig. 6, hatched area). The same method was performed for reconstruction of the lateral margins of the jugal and squamosal (see Fig. 3, hatched area).

\section{SYSTEMATIC PALEONTOLOGY}

SAUROPTERYGIA Owen, 1860

Order PLESIOSAURIA de Blainville, 1835

Family ELASMOSAURIDAE Cope, 1869

LIBONECTES MORGANI Carpenter, 1997

Holotype-SMUSMP 69120, skull and mandible, atlas-axis complex, 48 successive cervical vertebrae, fragmentary thoracic ribs, gastralia and associated gastroliths (Sachs and Kear, 2015); late Cenomanian; Britton Formation, Eagle Ford Group, Near Cedar Hill, Dallas County, Texas, U.S.A.

Referred Specimen-SMNS 81783, skull and mandible, atlas-axis complex. Middle Turonian (Upper Cretaceous) Unit T2a (Ettachfini and Andreu, 2004) of the CenomanianTuronian limestone bar, north of Goulmima, Er-Rachidia Province, Southern Morocco.

\section{DESCRIPTION}




\section{General Preservation}

The skull of SMNS 81783 is slightly laterally crushed but most of the bones remain in their natural arrangement and only some parts are missing, including the most dorsal part of the parietal crest, the left lateral margin of the temporal fenestra, and both squamosal arches. The right maxilla is almost dissolved, so that only a small part is preserved. The left part of the palate is broken and disarticulated but much of the right side, posterior to the internal nares is well preserved. The identification of the sutures between palatal bones is difficult and the narial region is crushed and difficult to interpret. The mandible is almost completely preserved except its lateral margin and the posterior part of the right dentary, and it is in occlusion with the cranium.

\section{Skull}

We estimate that the original cranial length was about $295 \mathrm{~mm}$ long from the tip of the premaxilla to the occipital condyle (see measurements and skull proportions in Table 1). The beak index (percentage of the preorbital length to the entire length of the skull; Welles, 1952) represents $42 \%$ of the skull length. In most elasmosaurids, this value is close to $40 \%$, whereas it is close to 55\% in Polycotylidae (Buchy et al., 2005). The temporal fossae are estimated to have occupied about $40 \%$ of the skull length. A similar ratio (35-40\%) is observable in Cretaceous Elasmosauridae (Sato et al., 2006).

Premaxillae - Each premaxilla bears five teeth and participates to the external naris (Fig. 3B), constituting its anterior and medial margins. The flat dorsal surface of the premaxilla is slightly pitted and bears a clearly visible suture between both premaxillae (Fig. 3A). SMNS 81783 possesses a slight transverse 'rostral' constriction between the premaxilla and the maxilla (Fig. 3A), as observed in many large-headed plesiosaurians (e.g., Taylor, 1992; O'Keefe, 2001; Druckenmiller and Russell, 2008; Smith and Dyke, 2008) and in some 
elasmosaurids (e.g., Vincent et al., 2011). A small diastema forms a small concavity between the last premaxillary and the first maxillary teeth (Fig. 3C). The premaxilla-maxilla suture originates posterior to the fifth premaxillary alveolus and extends posterodorsally to a point just anterodorsal to the external naris (Fig. 3C). The posterolateral extension of the premaxilla at the level of the posterior narial border is unclear (Fig. 3A, C) and it is impossible to confirm the presence of a prefrontal and its possible extension. In dorsal view, at the level of the interorbital region, the posterior process of the premaxilla forms a shallow concavity separating the frontals (Fig. 3A). The posterior extension of the premaxillae is long and shows a small contact with the parietal at the level of the last third of the orbital length (Fig. 3A). This feature is seen in many Late Cretaceous elasmosaurids (Sato et al., 2006), polycotylids and some pliosaurids (Ketchum and Benson, 2010). A small isolated piece of bone, located dorsally in the interorbital region, is preserved dorsally to the concavity of the posterior processes of the premaxillae (Fig. 3A). It is tentatively interpreted as part of the premaxilla, since it matches perfectly with the concavities of the posterior processes of the premaxillae, and covers the sutures between the premaxillae and the frontal. In ventral view, the palatal surface of the premaxillae exhibit an alveolar channel connecting the replacement alveoli (Fig. 3B).

Maxillae - The right maxilla is severely damaged; only a small piece of its preorbital part is present (Fig. 3C). The left maxilla is well-preserved and shows 15 alveoli (Fig. 3C). The maxilla forms the lateral, ventral and posteroventral margins of the external naris, and the anterior corner of the orbit (Fig. 3A, C) as in Libonectes morgani (Carpenter, 1997). Anterior to the orbit, the sutures between the maxilla and the frontal-prefrontal are not observable (Fig. 3A, C). Laterally, the maxilla extends beneath the orbit and underlaps the jugal ventrally (Fig. 3C). The maxilla-jugal suture is long and posteroventrally directed as in other elasmosaurids (e.g., Sato et al., 2006:Futabasaurus suzukii) and it extends posteriorly to about half the 
length of the temporal fenestra. Its suture with the squamosal is unclear (Fig. 3C), as is the participation of the maxilla in the margin of the internal naris in palatal view (Fig. 3B).

Nares - The external nares are located above the third to fifth maxillary teeth (Fig. 3C), just anterior to the orbits. The anterior extension of the external nares is difficult to determine (Fig. 3A, C). The internal nares (Fig. 3B) largely overlap the external ones but are located slightly anteriorly to them, as in Libonectes morgani (Carpenter, 1997).

Frontal-The frontal forms the roof of the orbit (Fig. 3A). It contacts the premaxillae medially and the postfrontal posterolaterally (Fig. 3A). It does not seem to contribute to the temporal fenestra but, because of the bad preservation of this area, it is not possible to comment on its contact with the maxillae. The frontals are separated by the long dorsal processes of the premaxillae along their entire length, as in most elasmosaurids (Vincent et al., 2011), but unlike the condition of all Jurassic and a few Cretaceous taxa (Brancasaurus and Callawayasaurus) that exhibit frontals in contact all along their length (Carpenter, 1997, 1999; Sato, 2003; Kear, 2005; Brown et al., 2013). Around the posterior orbital margins, the sutural relationships between the frontal, premaxillae, parietal, postfrontal and postorbital are difficult to interpret (Fig. 3A). Ventrally, the frontals form the lateral wall of the olfactory sulcus (Fig. 3C).

Orbits - The maxilla forms the anterolateral corner of the orbit (Fig. 3A, C) but it is not clear whether the maxilla or the prefrontal form their anteromedial corner. The frontal and the jugal form respectively its dorsal and ventral edges (Fig. 3A, C), as in Libonectes morgani, Styxosaurus and Thalassomedon (Carpenter, 1997). The ventral margin formed by the maxillae appears convex in lateral view (Fig. 3C), as in many elasmosaurids (Sato et al., 2006). Similarly as in most known elasmosaurid skulls (e.g., Sato, 2003:Terminonatator), the sclerotic ring is not preserved. 
Postorbital Bar-The postorbital bar is partially preserved on both sides (Fig. 3A). The exact of its contacts with the frontal and postfrontal, as well as its relationships with the posterior rim of the orbits, and its possible contact with the squamosal posteriorly are unclear.

Jugal-The jugal is a plate-like, transversely thin bone that forms the most part of the ventral margin of the orbit (Fig. 3C), as in Libonectes morgani and Futabasaurus (Carpenter, 1997; Sato et al., 2006). The left jugal is rather well preserved, contrary to the right, but the suture with the postorbital is not easily observable (Fig. 3A). Posterior to the orbit, a large foramen perforates the lateral surface of the jugal (Fig. 3C), as in Libonectes morgani (Welles, 1949). It is not possible to differentiate the squamosal from the posterior part of the jugal (Fig. 3C).

Parietal-The closed parietals form a median dorsal roof over the endocranial cavity, with lateral surfaces weakly concave. The exact height of the parietal crest is unknown because of partial dissolution (Fig. 3C). Anteriorly, the parietal contacts the frontal at the level of the posterior margin of the orbit (Fig. 3A). A small pineal foramen is present anteriorly and totally enclosed within the parietals at the level of the postorbital bar (Fig. 3A). The pineal foramen is absent in most elasmosaurids (Futabasaurus suzukii, Libonectes morgani, Styxosaurus snowii, Terminonatator ponteixensis, Tuarangisaurus keyesi, Zarafasaura oceanis) but present in Callawayasaurus (Welles, 1952). Its loss is considered as a synapomorphy of Late Cretaceous Elasmosauridae and Polycotylidae by Carpenter (1997), but recent phylogenetic data sets suggest that the pineal foramen was lost independently in some Cretaceous elasmosaurids (e.g., Eromangasaurus) and some polycotylids (O’Keefe, 2001; Kear, 2005; Druckenmiller and Russell, 2008; Ketchum and Benson, 2010). The posterior end of the parietal overlaps the supraoccipital.

Squamosal—Both squamosals are partially preserved (Fig. 3A, C); their medial contact is not preserved. The left dorsal ramus has been lost, along with the medial dorsal 
portion of the right ramus. The anterior and ventral rami are preserved on the right side and show that the suspensorium was only slightly inclined anterodorsally (Fig. 3A), in contrast to the straight suspensorium present in Terminonatator (Sato, 2003) or the curved one (posterior margin is convex in lateral view) of Styxosaurus and Thalassomedon (Carpenter, 1999). The right anterior ramus of the squamosal forms the temporal bar, contacting the jugal anteriorly (Fig. 3A). The sutural relationships of the ventral ramus of the squamosal with the quadrate remains unclear. On the right side, medial to the quadrate, the squamosal is overlain by the quadrate ramus of the pterygoid.

Quadrate - The right quadrate is poorly preserved but the left one is almost complete (Fig. 3A, C), though its most posterior surface is dissolved. The left quadrate seems to be mediolaterally convex in posterior view and concave in anterior view. It extends anteromedially to contact the quadrate ramus of the pterygoid (Fig. 3A, B). Ventrally, the quadrate extends well ventral to the tooth row (Fig. 3C), being the thickest at the articulation with the mandible to form a large quadrate condyle. The latter is divided into two parts by an oblique, anteroposteriorly oriented intercondylar depression. Both quadrates have a small depression on their medial surface corresponding to the facet of the paraoccipital process (Fig. 3A).

Vomer-The vomer is poorly preserved; its anteriormost part is missing (Fig. 3B), and the occurrence of a vomeronasal foramen cannot be determined. The vomer forms the anterior and medial margins of the internal naris (Fig. 3B). Its posterior extension and its sutural relationships with the pterygoid are unclear. The median suture between the two vomers is clearly seen in the median sheet of bone separating the internal nares (Fig. 3B).

Palatine - The palatine is well-preserved on the right side of the palate (Fig. 3B), though some parts are partially broken and its sutural relationships with the pterygoid are not 
visible. On the left side the palatine is strongly damaged (Fig. 3B). The anterior extension of the palatine, as well as its participation to the naris margin are unclear (Fig. 3B).

Pterygoid - The right pterygoid is well preserved, while the left one is damaged in a similar manner to the left palatine (Fig. 3B). The pterygoids form the central plate-like portion of the palate, posterior to the vomers and anterior to the posterior interpterygoid vacuities (Fig. 3B). Both pterygoids are broken anterior to the posterior interpterygoid vacuities, obscuring their midline suture. Our interpretation is that there is no anterior interpterygoid vacuity and that the pterygoids are closed along their median suture (Fig. 3B), as in the Jurassic microcleidids, Microcleidus tournemirensis and Microcleidus homalospondylus (Brown et al., 2013), as well as in the Cretaceous elasmosaurids (Bardet et al., 1999; Großmann, 2007). Lateral to the narrow and elongated posterior interpterygoid vacuities, the ventral surface of the pterygoid is slightly concave and its lateral margin is projected ventrolaterally, forming a curved prominent flange that contacts posteriorly the quadrate ramus (Figs. 3B, 4). On the right side, the pterygoid bears an anteroposteriorly extended opening located laterally to the posterior interpterygoid vacuity (Figs. 3B, 4). Despite a poor preservation of this area on the left side, an opening on the left pterygoid appears present as well. These openings are exactly mirrored on the left and right pterygoids (Fig. 3B), which suggests that they are most likely not taphonomic artefacts. Such openings were reported in Zarafasaura as a possible autopomorphy of the taxon (Vincent et al., 2011). Posterior to the interpterygoid vacuities, the bones are dissolved and it is not possible to comment on the medial contact between the pterygoids covering the basioccipital (Fig. 3B).

Epipterygoid-The epipterygoid forms a thin vertical process lateral to the parabasisphenoid (Fig. 4). The epipterygoid seems to extend dorsally from the anterior dorsal edge of the vertical pterygoid process, similarly to that observed in Libonectes morgani (Carpenter, 1997). 
Ectopterygoid - The ectopterygoid is a C-shaped bone located posterolaterally to the palatines and laterally to the pterygoids (Fig. 3B, 4). The suture between the pterygoid and ectopterygoid, though unclear, appears possibly located near the bump formed by the ectopterygoid (Fig. 3B). A facet is visible on the lateral margin of the ectopterygoid and seems to contact the posterior elongation of the maxillary (Fig. 4). At the juncture of the right palatine with the ectopterygoid and pterygoid, a small fenestra is present and may correspond to the suborbital fenestra (Fig. 3B), as seen in Libonectes morgani (Carpenter, 1997). The poor preservation of the left pterygoid precludes observation of this fenestra on that side.

\section{Braincase}

The braincase is formed by the supraoccipital, the fused exoccipital-opisthotics, the basioccipital, the prootic, and the parabasisphenoid. The elements are slightly displaced from their natural position. The foramen magnum is taller than wide and seems to be slightly constricted at the level of the supraoccipital-exoccipital-opisthotic sutures.

Parabasisphenoid - The parasphenoid and the basisphenoid form the anterior floor of the braincase and there is no trace of suture between the dorsal part of the parasphenoid and the ventral part of the basisphenoid. Anteriorly, the cultriform process of the parasphenoid is visible on the palatal surface (Fig. 5A, B, C) where it terminates between the posterior ends of the anterior rami of the pterygoids. The parasphenoid carries a prominent ventral keel that divides the posterior interpterygoid vacuities (Figs. 3B, 5B), as in Cretaceous elasmosaurids and in the Jurassic forms Microcleidus tournemirensis and Microcleidus homalospondylus (Bardet et al., 1999; Brown et al., 2013). The ventral keel continues slightly posterior to the posterior margins of the interpterygoid vacuities and tapers posteriorly along the ventral surface of the basioccipital (Fig. 3B). In dorsal view, just posterior to the cultriform process, the sella turcica is open anteriorly (Fig. 5A). The pituitary fossa occupies about one-third of 
the braincase floor, which is comparable to the condition in Tricleidus Andrews, 1909 (see Sato et al., 2011). The sella turcica posteriorly terminates with the dorsum sellae (Fig. 5A, C). A prominent pila antotica extends anterodorsally from this region, and a pila metoptica is present more anteriorly (Fig. 5A, B, C), as in Thalassiodracon (Benson et al., 2011). In lateral view and ventrally to the pila antotica, a process extends from the lateral surface of the basisphenoid (Fig. 5B) and forms a facet that contacts the pterygoid (basipterygoid process). The lateral surface of the parabasisphenoid is pierced by a large foramen for the internal carotid located ventral to the pila antotica and just posterior to the basipterygoid process of the basisphenoid (Fig. 5B). In anterior view, a pair of internal carotid foramina penetrates the posterior wall of the sella turcica (Fig. 5C), as in Libonectes morgani (Carpenter, 1997:fig. 5) but differs from Alexandronectes zealandiensis in which there is only a single foramen in the floor of the sella turcica (Otero et al., 2016). The dorsolateral side of the pituitary fossa bears a foramen visible in anterior view (Fig. 5C) that probably carried the abducens nerve (Carpenter, 1997).

Basioccipital—The basioccipital is a stout element. Its dorsal surface bears two facets (Fig. 5C) for articulation with the exoccipitals (otooccipital facets: Evans, 2012). A small portion of the basioccipital median ridge seems to be present in dorsal view (Fig. 5A, C). Ventrolaterally, the basioccipital tubers show two ovoid facets for contact with the pterygoids (Fig. 5B, D). In ventral view, the basioccipital contacts the parabasisphenoid anteriorly and the pterygoids laterally. Contrary to what is reported among pliosaurids and cryptoclidids (e.g., Andrews, 1913; Brown, 1993), in which the exoccipital-opisthotic forms part of the occipital condyle, the basioccipital appears here to form the entire rounded occipital condyle (Fig. 5D). A groove surrounds the occipital condyle forming a distinct neck ventrally and laterally (Fig. 5D) as in elasmosaurids (Brown, 1993), but differing from the condition of Thalassiodracon (Benson et al., 2011) or Plesiosaurus (O'Keefe, 2006), in which the 
occipital condyle is a shallow dome lacking a groove between the condyle and the body of the basioccipital.

Exoccipital-opisthotics-Both exoccipital-opisthotics are well preserved and are fused as in most plesiosaurians (e.g., Sato et al., 2011; Sachs et al., 2015). On the anterior surface, a deep chamber for the ampulla and utriculus is visible (Fig. 5E). Dorsally and laterally to these structures, two openings are preserved and correspond to the caudal part of the posterior and horizontal semicircular canals, respectively (Fig. 5E). Two foramina pierce the medial surface of the exoccipital adjacent to its ventral surface (Fig. 5E). The more anterior foramen is larger and might have served for passage of the glossopharyngeal nerve (IX) and possibly also for the perilymphatic duct (Sachs et al., 2015). The smaller one may be considered as a foramen for the vagus and accessory nerves $(\mathrm{X}+\mathrm{XI})$ as well as the jugular vein (Sachs et al., 2015). Anteriorly, the opisthotic forms the posterior margin of the fenestra ovalis (Fig. 5B). This character differs from the hypothesis proposed by Maisch (1998) for Muraenosaurus in which the opisthotics did not contribute to the fenestra ovalis. The straight paroccipital process has an anteroposteriorly oval cross section and is ventrally inclined (Fig. 5A, B, D). Its distal end is a little expanded but does not form a spatulate terminus as observed in pliosaurids and basal plesiosaurians (e.g., Smith and Dyke, 2008; Benson et al., 2011).

Prootic - The prootic occurs anteriorly to the exoccipital-opisthotic, and forms the anterior margin of the keyhole-shaped fenestra ovalis seen in lateral view (Fig. 5B). The prootic is a rectangular element, containing the anterior part of the vestibule of the inner ear dorsomedially (Fig. 5E). The facet for the supraoccipital faces posterodorsally and is pierced by an opening for the anterior semicircular canal (Druckenmiller, 2002; Sato et al., 2011). A much larger foramen on the exoccipital-opisthotic facet (Fig. 5E) is the exit for the horizontal 
semicircular canal (Sato et al., 2011). A foramen at the posterior part of the prootic base may represent the exit for cranial nerve VII (Carpenter, 1997).

Supraoccipital-The supraoccipital is a small arch-shaped element lying above the braincase (Fig. 5D) and below the parietal, enclosing the dorsal and dorsolateral margins of the foramen magnum. The supraoccipital contacts the parietal dorsally. Its ventrolateral portions are expanded anteroposteriorly to accommodate part of the semicircular canals, as in Muraenosaurus (Maisch, 1998) and Thalassiodracon (Benson et al., 2011). It also contacts the prootic anteroventrally and the exoccipital-opisthotic posteroventrally.

Stapes-Ventrally to the exoccipital-opisthotics and prootics, two anteroposteriorly oriented rods may correspond to the stapes (Fig. 5B). The two elements are $28 \mathrm{~mm}$ in length but the right one is broken in the middle. Stapes are commonly preserved in Lower Jurassic plesiosaurians (e.g., Brown et al., 2013), but rarely reported among Middle-Upper Jurassic or Cretaceous taxa (Sato et al., 2011), and some authors hypothesized that these taxa may have lacked stapes (e.g., Carpenter, 1997). Contrary to the stapes identified by Storrs and Taylor (1996) that contacts the anterior surface of the opisthotic (Benson et al., 2011), the stapes in SMNS 81783 does not contact any other element and its anterior end reaches the anterior extremity of the prootic base.

\section{Mandible}

Dentary - The dentary is a long and straight bone that occupies most of the lateral surface of the mandible. In dorsal view, the left and right dentaries unite at their anterior ends near alveoli positions 4 (Fig. 6A), to form a narrow, gracile and slightly elongated mandibular symphysis, as observed in Callawayasaurus (bearing three to five pairs of teeth) and Hydrotherosaurus (bearing three pairs). The symphysis, which represents $15 \%$ of the total skull length, is not laterally expanded and straight in lateral view (Fig. 6C). The dentary 
seems to be the only component of the symphysis, and it seems that the coronoid extends anteriorly up to the last third of the mandibular ramus. The suture between the dentary and the splenial are only visible anteriorly to the coronoid (Fig. 6C); however, the anterior extension of the splenial is unclear. The tooth number is difficult to define since only the medial margin is preserved; however, we estimate the original presence of 16 teeth on the dentary (Fig. 6A). Medially to these teeth, the alveoli for the replacement teeth are visible (Fig. 6A).

Coronoid - The coronoid (preserved on both sides) lies in tight contact with the dentary, on the medial surface of the mandible (Fig. 6A, C). It is a thin and triangular bone with a large dorsal inflation (Fig. 6C), comparable to that described in Zarafasaura (Vincent et al., 2011). It contacts the dentary anteriorly, the prearticular ventrally, and the surangular posteriorly.

Prearticular-The prearticular is a narrow bone that contacts the coronoid dorsally and the dentary ventrally; its anterior end is not preserved (Fig. 6C). Medially, the prearticular covers the posterior part of the Meckelian canal. The cast of the Meckelian canal visible in lateral view seems to be narrow anteriorly and to expand posteriorly (Fig. 6C). The mandibular foramen is only visible medially, located between the coronoid and the prearticular (Fig. 6C), where it opens largely posteriorly although the termination of the foramen cannot be confidently traced posterior to this region, due to the poor preservation of the bones in the posterior part of the mandible. The glenoid fossa appears just posterior to the occipital condyle.

Surangular-Only the left surangular is partially preserved (Fig. 6C). Its anterior part is developed dorsoventrally and forms a ridge that becomes flattened on its posterior part. In the posterior part of the mandible and posterior to the coronoid, the surangular descends to the glenoid cavity. 


\section{Teeth}

The teeth (Fig. 3) are slightly flattened and oval in cross-section as in Callawayasaurus, Terminonatator, Styxosaurus and Libonectes (Sachs and Kear, 2015). The two first teeth on the premaxillae are small and procumbent, as in Libonectes morgani and Dolychorhynchops osborni (Carpenter, 1997). The second and fourth premaxillary teeth are the largest. Several alveoli for replacement teeth are observable on the premaxillae and the left maxilla in palatal view. The maxillary teeth are poorly preserved, but appear to diminish in size from anterior to posterior, in contrast to the condition in Aristonectes (Gasparini et al., 2003b; Otero et al., 2014) and Kaiwhekea katiki (Cruickshank and Fordyce, 2002).

\section{Atlas-Axis Complex}

The conjoined atlas-axis centrum (Fig. 7) is cylindrical and distinctly longer than high, as illustrated in a number of other elasmosaurids (e.g., Welles, 1943; Sachs, 2005; Kubo et al., 2012; Otero et al., 2014; Sachs and Kear, 2015). The atlantal cotyle is circular and deeply concave. The cotylar rim is surrounded by a thin edge that is damaged along its left lateral margin; a posteriorly tapering notch incises its dorsal midline. Ventrally, the atlas intercentrum bears a prominent hypophyseal ridge similar to that reported in Elasmosaurus platyurus (Sachs, 2005), Eromangasaurus australis (Kear, 2005), Albertonectes vanderveldei (Kubo et al., 2012), Libonectes morgani (Sachs and Kear, 2015) and Vegasaurus molyi (O’Gorman et al., 2015). The anteroventral extremity of the hypophyseal ridge is flattened and elliptical in outline, as recorded in A. vanderveldei (Kubo et al., 2012) and L. morgani (Sachs and Kear, 2015). Posteriorly, the hypophyseal ridge forms a narrow crest merging with the articular face of the axis centrum. The atlas neural spine is oriented posteriorly, narrow on its base and flared dorsally. Only the ventral part of the neural spine is preserved. The exact height is unknown, and the contact between the atlas and axis neural arches seems perforated 
by a large intervertebral foramen, similar to that depicted in Libonectes atlasense (Buchy, 2005), L. morgani (Sachs and Kear, 2015) but also in V. molyi (O'Gorman et al., 2015) and Tuarangasaurus keyesi (Wiffen and Moisley, 1986). The atlas ribs, situated at the approximate mid-section of the atlas-axis complex, are fused to the axis ribs so that they cannot be distinguished from each other. The rib complex is projected laterally posteroventrally (about $45^{\circ}$ from the horizontal), beyond the articular face of the axis centrum. The concave and rounded articular face of the axis is partially preserved. It seems surrounded by a thickened convex rim.

\section{PHYLOGENETIC ANALYSIS}

In order to infer the phylogenetic relationships of SMNS 81783 within Plesiosauria, a cladistic analysis was performed using the datasets of Benson and Druckenmiller (2014), plus two additional OTUs: SMNS 81783 and the type specimen of Libonectes atlasense (see Appendix 1 and Supplementary Data 1). The scores of Libonectes morgani were modified following Sachs and Kear (2015). Yunguisaurus liae Cheng et al., 2006 was specified as the outgroup taxon and all characters were coded as unordered and unweighted.

A heuristic search for the most parsimonious trees was performed using TNT 1.1 (Goloboff et al., 2008). The search resulted in 100 parsimonious trees; the strict consensus is shown in Figure 8. The consensus tree has a tree length of 1345 steps, an ensemble consistency index of 0.24 , and an ensemble retention index of 0.62 . Bremer indices higher than one are indicated for each node shown in Figure 8.

The results of the phylogenetic analysis place SMNS 81783 within the Elasmosauridae (Bremer index $=3$ ), as sister taxon to Libonectes morgani and Libonectes atlasense. Two synapomorphies (ACCTRAN) unite the three taxa: the posterior extent of maxillary tooth row 
ventral to the postorbital bar and the heterodont maxillary dentition. SMNS 81783 presents three autapomorphies (ACCTRAN): the presence of a transverse constriction of the rostrum at the premaxillae-maxilla suture, the absence of a dorsomedian ridge on the premaxillae and the short anterior extension of the parietal to the level of the temporal bar. The clade formed by $L$. morgani and L. atlasense is supported by one autapomorphy (ACCTRAN): the absence of a pineal foramen.

\section{DISCUSSION}

\section{Comparisons with other elasmosaurids}

SMNS 81783 presents several elasmosaurid characters: (1) the anterior tooth with an oval cross section (Ketchum and Benson, 2010:character 109); (2) absence of an anterior interpterygoid vacuity (Bardet et al., 1999:character 12; Vincent et al., 2011:character 23); (3) high coronoid eminence (Vincent et al., 2011:character 39); (4) a keyhole-shaped foramen magnum (Druckenmiller and Russell, 2008:character 67). In addition, SMNS 81783 displays a combination of characters variably found in other elasmosaurids: (1) five premaxillary teeth (Brown, 1993; Sato, 2002); (2) a dorsomedial process of the premaxilla contacting the anterior extension of the parietal (Kear, 2005); (3) a pineal foramen present but not bordered by the frontal (Kear, 2005); (4) a convex ventral margin of the orbit (Sachs and Kear, 2015); (5) a keel on the ventral surface of the parabasisphenoid (Kear, 2005). Comparisons with the available elasmosaurid skulls (see Table 2) show that the flat dorsal surface of the premaxillae in SMNS 81783 differs from the prominent dorsomedial bump situated anteriorly to the orbit in Futabasaurus, Styxosaurus, and Terminonatator (Sato, 2003; Sato et al., 2006), the prominent dorsomedian ridge present in Eromangasaurus (Kear, 2005) or the low keel reported dorsally along the midline of the premaxillae in Elasmosaurus (Sachs, 2005). 
Moreover, in SMNS 81783 the premaxillae bear in total 10 teeth, contrary to the conditions in Eromangasaurus (7), Elasmosaurus (12), Terminonatator (9), Kaiwhekea (7) or Aristonectes (10-13 teeth) (Carpenter, 1999; Cruickshank and Fordyce, 2002; Gasparini et al., 2003b; Sato, 2003; Kear, 2005). In SMNS 81783, the external nares are oval and located above the third to fifth maxillary tooth, just anterior to the orbit. This condition differs from the circular external nares found in Thalassomedon (Carpenter, 1999), and from the position of the external nares located above the sixth and seventh maxillary teeth in Styxosaurus or above the second and third ones in Tuarangisaurus (Carpenter, 1999). The size variability in the maxillary dentition that incorporates teeth with an oval cross-section in SMNS 81783 contrasts with the relatively small and consistently sized dentition occurring in Aristonectes and Kaiwhekea (Cruickshank and Fordyce, 2002; Gasparini et al., 2003b), and the rounded tooth cross sections of Eromangasaurus (Kear, 2005) and Terminonatator (Sato, 2003). The ventral margin of the orbit in SMNS 81783 is convex and mainly formed by the jugal, in contrast to that reported for Thalassomedon and Zarafasaura, in which the jugal forms only one-third of the ventral margin of the orbit (Carpenter, 1999; Vincent et al., 2011), or Hydrotherosaurus, in which the jugal is excluded from the orbital margin (Welles, 1943) and Futabasaurus that has a straight ventral margin of the orbit (Sato et al., 2006). The pineal foramen present in SMNS 81783 is absent in Futabasaurus, Hydrotherosaurus, Styxosaurus, Tuarangisaurus, Terminonatator and Zarafasaura (Welles, 1943; Sato, 2003; Vincent et al., 2011). Moreover, in SMNS 81783, the pineal foramen is totally enclosed by the parietals, contra that observed in Callawayasaurus where the frontal forms the anterior border of the pineal foramen (Welles, 1952). In SMNS 81783, the anterior margin of the parietal contacts the frontal at the level of the posterior margin of the orbit, differing from the situation in Aristonectes, in which the parietal terminates more anteriorly between the orbits (Gasparini et al., 2003b). The mandible of SMNS 81783 presents a Meckelian canal not open for most of 
its length contrary to the conditions in Callawayasaurus and Terminonatator (Welles, 1962; Sato, 2003), and a high coronoid, in contrast to that observed in Eromangasaurus (Kear, 2005). The mandibular symphysis in SMNS 81783 reaches the fourth tooth pair, unlike in Hydrotherosaurus (3 pairs), Terminonatator, Futabasaurus (2-3 pairs) and Aristonectes (one pair). Moreover, the mandibular symphysis represents $15 \%$ of the total skull length, contrary to the condition in Eromangasaurus (23\% of the skull length), Tuarangisaurus (6\%) and Zarafasaura (8\%) (Vincent et al., 2011). The characters presented by SMNS 81783 differentiate this specimen from most of the elasmosaurid taxa, except Libonectes, with which many similarities have been found.

\section{Comparison with Libonectes}

The diagnosis for Libonectes established by Carpenter (1997) is principally based on postcranial characters and difficult to apply for SMNS 81783, which presents only a skull and the atlas-axis complex. The only diagnostic cranial character proposed by Carpenter (1997) concerns the preorbital length/skull length ratio, but according to the author, this character has a limited taxonomic utility (Carpenter, 1997:214). The anatomical comparisons between SMNS 81783 and the other elasmosaurids allow its referal to Libonectes. Moreover, the phylogenetic result obtained in this study recovers a sister group relationship with the two species of Libonectes, supporting the hypothesis proposed by Buchy (2005).

The comparison with the holotypes of Libonectes morgani and Libonectes atlasense reveals only a few differences between the three specimens. A pineal foramen is present in SMNS 81783 but not in L. morgani and L. atlasense. The virtual reconstruction of SMNS 81783 reveals the presence of this structure, but it appears hardly visible because of its small size (diameter $=5 \mathrm{~mm})$ as well as its limited depth $(4 \mathrm{~mm})$. This structure is possibly not observable in L. morgani and L. atlasense because of the poor preservation of the interorbital 
region (see Carpenter, 1997; Buchy, 2005). Lateral to the posterior interpterygoid vacuities, the ventral surface of the pterygoid in SMNS 81783 is dorsally concave and its lateral margin is projected ventrolaterally, forming a curved prominent flange. This contrasts with the description of L. morgani given by Carpenter (1997), in which the pterygoids are plate-like structures (Carpenter, 1997:203). However, the illustrations of Welles (1949:pl. 3) and Druckenmiller and Russell (2008:12, fig. 6), as well as the revised character score performed by Sachs and Kear (2015:char. 100), show that the pterygoids of L. morgani are dorsally concave and similar to those of SMNS 81783. The pterygoids are not visible in L. atlasense (Buchy, 2005). The openings situated on the pterygoids lateral to the posterior interpterygoid vacuities found in SMNS 81783 are absent in L. morgani and not observed in L. atlasense. A reasonable doubt remains concerning the real nature of these openings that could correspond to an artefact of preservation. The dorsomedian ridge found on the dorsal surface of the premaxillae in L. morgani (Sachs and Kear, 2015) and L. atlasense (Buchy, 2005:fig. 2) is not present in SMNS 81783, in which the premaxillae appear flattened on their dorsal surface. The dorsomedian ridge found in L. morgani was not reported in the description of Carpenter (1997), while Welles (1949:8) and Sachs and Kear (2015:696) described the prominent dorsomedian ridge on the premaxillae as a feature distinguishing L. morgani from other Elasmosauridea. The ventral emargination between the third premaxillary and the third maxillary teeth is concave in L. atlasense (Buchy, 2005) but straight in L. morgani (Carpenter, 1997:fig. 2) and SMNS 81783. The mandibular symphysis comprises six teeth in L. atlasense (Buchy, 2005) but eight in L. morgani (Carpenter, 1997:fig. 2) and SMNS 81783. It appears difficult to state if SMNS 81783 is more related to Libonectes morgani or to Libonectes atlasense. Buchy (2005) proposed four diagnostic cranial characters allowing to differentiate L. atlasense from L. morgani: (1) the ventral emargination between the third premaxillary and the third right (fifth on the left) maxillary teeth is concave; (2) the external 
naris is situated at the level of the fourth to fifth maxillary teeth, which are the largest teeth in the maxillary tooth row; (3) the mandibular symphysis comprises three teeth; (4) the mandibular symphysis is flat, posteroventrally oriented and extends to the anterior end of the maxilla. SMNS 81783 differs from $L$. atlasense on all these characters and is thus more similar to L. morgani. Based on the differential diagnosis proposed by Sachs and Kear (2015), SMNS 81783 nevertheless differs from L. morgani, based on two characters: the presence of a pineal foramen and the absence of a prominent dorsomedian ridge on the premaxillae. These differences might however be related to different states of preservation for the specimens of these taxa, the intraorbital region being not well preserved in L. morgani. Similarly a doubt remains about the prominent dorsomedian ridge on the premaxillae, the absence or presence of such a structure being possibly part of an intraspecific variability (e.g., sexual dimorphism), which is still unknown among plesiosaurians.

The relationships among the different OTUs referred to this genus remain unresolved. Based on the limited differences, we refer SMNS 81783 to Libonectes morgani, but the comparison between L. morgani and L. atlasense is not clear because of the lack of comparative data. The type specimen of L. morgani is essentially known from its cranial characters and presents $24 \%$ of missing cranial data in the phylogenetic analysis of Benson and Druckenmiller (2014). Conversely, L. atlasense presents $80 \%$ of missing cranial data and SMNS 81783 has an intermediate value with $50 \%$ of missing cranial data. The use of computed tomography on the type specimen of L. atlasense would enable to provide new information about its cranial characters, and to clarify the relationships among the specimens referred to Libonectes.

\section{Paleobiogeography and Paleoecological Interpretations}


The assignation of SMNS 81783, from the Turonian of Morocco, to Libonectes morgani, a North American taxon previously only known from the Late Cenomanian of Texas (Sachs and Kear, 2015), greatly enlarges the palaeobiogeographical distribution of this species. Some affinities between North American and North African faunas have already been noted for other Turonian vertebrate taxa, more specifically between teleostean fishes (Cavin et al., 2010), but also for a pliosaurid specimen referred to Brachauchenius lucasi (Angst and Bardet, 2015).

Thanks to the particular preservation of the fossil (nodule) and the use of computed microtomography, some structures that are rarely preserved and difficult to observe, such as the pineal foramen and the stapes, could be identified in SMNS 81783. The pineal foramen is considered as lacking in many derived elasmosaurids (e.g., Wiffen and Moisley, 1986; Carpenter, 1997; Bardet et al., 1999; Sato, 2003). Its condition (small and shallow) in SMNS 81783 raises questions relative to its true or artefactual absence in advanced elasmosaurids. In addition, the absence of stapes was considered as a synapomorphy of Elasmosauridae (Carpenter, 1997) but its occurrence in the elasmosaurids Tuarangisaurus keyesi (O'Gorman et al., 2017) and SMNS 81783 challenges this hypothesis. According to Sato et al. (2011), it is possible that some plesiosaurians lacked an ossified stapes. However, the morphology of the thin and fragile stapes found in SMNS 81783 likely suggests that its supposed absence in most elasmosaurid specimens is possibly due to their poor state of preservation.

\section{CONCLUSION}

The use of computed microtomography provides new anatomical information of a Moroccan plesiosaurian specimen difficult to study by direct observation because of its particular mode of preservation. The digital reconstruction of SMNS 81783 confirms its 
position within Elasmosauridae and its assignment to Libonectes, as previously suggested by Buchy (2005). The specimen was referred to Libonectes atlasense (Buchy, 2005), but our study indicates greater similarity to the North American taxon Libonectes morgani. A reexamination of the holotype of Libonectes atlasense using computed microtomography will help to clarify the morphological disparity with L. morgani.

\section{ACKNOWLEDGMENTS}

This work was supported by a grant from the Agence Nationale de la Recherche under the LabEx ANR-10-LABX-0003-BCDiv, in the program 'Investissements d'avenir' ANR-11IDEX-0004-02. We are grateful to the Staatliches Museum für Naturkunde Stuttgart for the loan of the specimen SMNS 81783 and to E. Maxwell for access to the collection of the Stuttgart museum. We thank the AST-RX platform at the MNHN for access to the CT-scan and M. Garcia Sanz (MNHN, UMS 2700 OMSI) for producing the CTscans, and F. Goussard (MNHN, UMR 7207 CR2P) for assistance with 3D digital reconstructions and imaging based on CT scans. We are very grateful to D. Germain (MNHN, UMR 7207 CR2P) for his help with the use of the phylogenetical software T.N.T. We thank S. Sachs (Naturkundemuseum Bielefeld, Abteilung Geowissenschaften, Germany) and B. Kear (Museum of Evolution, Uppsala University, Sweden) for general discussion. Finally, we want to thank P. Druckenmiller and both reviewers, Robin O'Keefe and Rodrigo Otero, for helpful comments and suggestions.

\section{LITERATURE CITED}


Andrews, C. W. 1909. On some new Plesiosauria from the Oxford Clay of Peterborough. Annals and Magazine of Natural History, London 48:418-429.

Andrews, C. W. 1911. Description of a new plesiosaur (Plesiosaurus capensis, sp. nov.) from the Uitenhage Beds of Cape Colony. Annals of the South African Museum 1:309-322.

Andrews, C. W. 1913. A descriptive catalogue of the Marine Reptiles of the Oxford Clay. Based on the Leeds Collection in British Museum (Natural History), Part II. British Museum (Natural History), London, 206 pp.

Angst, D., and N. Bardet. 2015. A new record of the pliosaur Brachauchenius lucasi Williston, 1903 (Reptilia: Sauropterygia) of Turonian (Late Cretaceous) age, Morocco. Geological Magazine 153:449-459.

Araújo, R., M. J. Polcyn, J. Lindgren, L. L. Jacobs, A. S. Schulp, O. Mateus, A. O. Gonçalves, and M. L. Morais. 2015. New aristonectine elasmosaurid plesiosaur specimens from the Early Maastrichtian of Angola and comments on paedomorphism in plesiosaurs. Netherlands Journal of Geosciences-Geologie en Mijnbouw 94:93-108.

Bardet, N., P. Godefroit, and J. Sciau. 1999. A new elasmosaurid plesiosaur from the Lower Jurassic of Southern France. Palaeontology 42:927-952.

Bardet, N., X. Pereda Suberbiola, and N. E. Jalil. 2003a. A new polycotylid plesiosaur from the Late Cretaceous (Turonian) of Morocco. Comptes Rendus Palevol 2:307-315.

Bardet, N., X. Pereda Suberbiola, and N. E. Jalil. 2003b. A new mosasauroid (Squamata) from the Late Cretaceous (Turonian) of Morocco. Comptes Rendus Palevol 2:607-616.

Bardet, N., A. Houssaye, J. C. Rage, and X. Pereda Suberbiola. 2008. The Cenomanian-Turonian (Late Cretaceous) radiation of marine squamates (Reptilia): the role of the Mediterranean Tethys. Bulletin de la Société Géologique de France 179:605-22. 
Benson, R. B. J., K. T. Bates, M. R. Johnson, and P. J. Withers. 2011. Cranial anatomy of Thalassiodracon hawkinsii (Reptilia, Plesiosauria) from the Early Jurassic of Somerset, United Kingdom. Journal of Vertebrate Paleontology 31:562-574.

Benson, R. B. J., M. Evans, and P. S. Druckenmiller. 2012. High diversity, low disparity and small body size in Plesiosaurs (Reptilia, Sauropterygia) from the Triassic-Jurassic boundary. PLoS ONE 7(3): e31838. doi:10.1371/journal.pone.0031838.

Benson, R. B. J., and P. S. Druckenmiller. 2014. Faunal turnover of marine tetrapods during the Jurassic-Cretaceous transition. Biological Reviews 89(1):1-23.

de Blainville, H. D. 1835. Description de quelques espèces de reptiles de la Californie, précédée de l'analyse d'un système général d'Erpétologie et d'Amphibiologie. Nouvelles Annales du Muséum (national) d'Histoire Naturelle de Paris 4:233-296.

Brown, D. S. 1993. A taxonomic reappraisal of the families Elasmosauridae and Cryptoclididae (Reptilia: Plesiosauria). Revue de Paléobiologie 7:9-16.

Brown, D. S., P. Vincent, and N. Bardet. 2013. Osteological redescription of the skull of Microcleidus homalospondylus (Sauropterygia, Plesiosauria) from the Lower Jurassic of England. Journal of Paleontology 87:537-549.

Buchy, M. C. 2005. An elasmosaur (Reptilia: Sauropterygia) from the Turonian (Upper Cretaceous) of Morocco. Carolinea 63:5-28.

Buchy, M. C., F. Métayer, and E. Frey. 2005. Osteology of Manemergus anguirostris n. gen. et sp., a new plesiosaur (Reptilia, Sauropterygia) from the Upper Cretaceous of Morocco. Palaeontographica, Abteilung A 272:97-120.

Cabrera, A. 1941. Un plesiosaurio nuevo del Cretáceo del Chubut. Revisita del Museo de la Plata (Neuvo Serio) 2:113-130. 
Carpenter, K. 1997. Comparative cranial anatomy of two North American Cretaceous plesiosaurs; pp. 191-216 in J. M. Callaway and E. L. Nicholls (eds.), Ancient Marine Reptiles. San Diego Academic Press, California.

Carpenter, K. 1999. Revision of North American elasmosaurs from the Cretaceous of the Western Interior. Paludicola 2:148-173.

Cavin, L. 1995. Goulmimichthys arambourgi n. g., n. sp., un Pachyrhizodontidae (Actinopterygii, Teleostei) d'une nouvelle localité a nodules fossilifères du Turonien inferieur marocain. Comptes Rendus de l'Académie des Sciences, Paris, Série IIa 321:1049-1054.

Cavin, L. 1997. Nouveaux Teleostei du gisement du Turonien inférieur de Goulmima (Maroc). Compte Rendus de l'Académie des Sciences de Paris 325:19-24.

Cavin, L. 1999. Occurrence of a juvenile teleost, Enchodus sp., in a fish gut content from the Upper Cretaceous of Goulmima, Morocco. Palaeontology 60:57-72.

Cavin, L. 2001. Osteology and phylogenetic relationships of the teleost Goulmimichthys arambourgi Cavin, 1995 from the Upper Cretaceous of Goulmima, Morocco. Eclogae Geologicae Helvetica 133:25-52.

Cavin, L., L. Boudad, S. Duffaud, L. Kabiri, J. Le Loeuff, I. Rouget, and H. Tong. 2001. L'évolution paléoenvironnementale des faunes de poissons du Crétacé supérieur du bassin du Tafilalt et des régions avoisinantes (Sud-Est du Maroc): implications paléobiogéographiques. Compte Rendu de l'Académie des Sciences de Paris, Sciences de la Terre et des planètes 333:677-683.

Cavin, L., H. Tong, L. Boudad, C. Meister, A. Piuz, J. Tabouelle, M. Aarab, R. Amiot, E. Buffetaut, G. Dyke, S. Hua, and J. Le Loeuff. 2010. Vertebrate assemblages from the early Late Cretaceous of southeastern Morocco: An overview. Journal of African Earth Sciences $57: 391-412$. 
Cheng, Y. N., T. Sato, X. C. Wu, and C. Li. 2006. First complete pistosaurid from the Triassic of China. Journal of Vertebrate Paleontology 26:501-504.

Cope, E. D. 1869. Synopsis of the extinct Batrachia and Reptilia of North America. Transactions of the North American Philosophical Society 14:1-252.

Cruickshank, A. R. I. 1997. A Lower Cretaceous pliosauroid from South Africa. Annals of the South African Museum 105:207-226.

Cruickshank, A. R., and R. E. Fordyce. 2002. A new marine reptile (Sauropterygia) from New Zealand: further evidence for a Late Cretaceous austral radiation of cryptoclidid plesiosaurs. Palaeontology, 45:557-575.

Dames, W. 1895. Die Plesiosaurier der süddeutschen Liasformation. Abhandlungen der Königliche Preussische Akademie der Wissenschaften zu Berlin 1895:1-83.

Druckenmiller, P.S. 2002. Osteology of a new plesiosaur from the Lower Cretaceous (Albian) Thermopolis Shale of Montana. Journal of Vertebrate Paleontology 22:29-42.

Druckenmiller, P. S., and A. P. Russell. 2008. A phylogeny of Plesiosauria (Sauropterygia) and its bearing on the systematic status of Leptocleidus Andrews, 1922. Zootaxa 1863:1-120.

Ettachfini, E. M., and B. Andreu. 2004. Le Cénomanien et le Turonien de la plate-forme Préafricaine du Maroc. Cretaceous Research 25:277-302.

Evans, M. 2012. A new genus of plesiosaur (Reptilia: Sauropterygia) from the Pliensbachian (Early Jurassic) of England, and a phylogeny of the Plesiosauria. Ph.D. dissertation, University of Leicester, 397 pp.

Ferrandini, M., J. Philip, J. F. Babinot, and G. Tronchetti. 1985. La plate-forme carbonatée du Cénomano-Turonien de la région d'Erfoud-Errechidia (Sud-Est marocain): stratigraphie et paléoenvironement. Bulletin de la Société Géologique de France 8:559-64.

Gasparini, Z., L. Salgado, and S. Casadi. 2003a. Maastrichtian plesiosaurs from northern Patagonia. Cretaceous Research 14:157-170. 
Gasparini, Z., N. Bardet, J. E. Martin, and M. Fernandez. 2003b. The elasmosaurid plesiosaur Aristonectes Cabrera from the latest Cretaceous of South America and Antarctica. Journal of Vertebrate Paleontology 23:104-115.

Goloboff, P. A., J. M. Carpenter, J. S. Arias, and D. R. M. Esquivel. 2008. Weighting against homoplasy improves phylogenetic analysis of morphological datasets. Cladistics 24:1-16.

Großmann, F. 2007. Preliminary description and phylogenetic position of a new plesiosaur (Reptilia: Sauropterygia) from the Toarcian of Holzmaden, Germany. Journal of Paleontology 78:973-988.

Kear, B. P. 2005. A new elasmosaurid plesiosaur from the Lower Cretaceous of Queensland, Australia. Journal of Vertebrate Paleontology 25:792-805.

Ketchum, H. F., and R. B. J. Benson. 2010. Global interrelationships of Plesiosauria (Reptilia, Sauropterygia) and the pivotal role of taxon sampling in determining the outcome of phylogenetic analyses. Biological Reviews 85:361-392.

Kubo, T., M. T. Mitchell, and D. M. Henderson. 2012. Albertonectes vanderveldei, a new elasmosaur (Reptilia, Sauropterygia) from the Upper Cretaceous of Alberta. Journal of Vertebrate Paleontology 32:557-572.

Lebedel, V., C. Lezin, B. Andreu, M. J. Wallez, E. M. Ettachfini, and L. Riquier. 2013. Geochemical and palaeoecological record of the Cenomanian-Turonian Anoxic Event in the carbonate platform of the Preafrican Trough, Morocco. Palaeogeography, Palaeoclimatology, Palaeoecology 369:79-98.

Lomax, D. R., and W. R. Wahl. 2013. A new specimen of the elasmosaurid plesiosaur Zarafasaura oceanis from the Upper Cretaceous (Maastrichtian) of Morocco. Paludicola 9:97-109.

Maisch, M. 1998. Notes on the cranial osteology of Muraenosaurus Seeley, 1874 (Sauropterygia, Jurassic), with special reference to the neurocranium and its implications for sauropterygian phylogeny. Neues Jahrbuch für Geologie und Paläontologie, Abhandlungen, 207:207-253. 
Novas, F. E., J. S. D’Angelo, J. P. O’Gorman, F. L. Agnolín, J. M. Lirio, and M. P. Isasi. 2015. First record of Polycotylidae (Sauropterygia, plesiosauria) from the Upper Cretaceous of Antarctica. Cretaceous Research 56:563-568.

O’Gorman, J. P., L. Salgado, E. B. Olivero, and S. A. Marenssi. 2015. Vegasaurus molyi, gen. et sp. nov. (Plesiosauria, Elasmosauridae), from the Cape Lamb Member (lower Maastrichtian) of the Snow Hill Island Formation, Vega Island, Antarctica, and remarks on Wedellian Elasmosauridae. Journal of Vertebrate Paleontology 35(3):e931285. 2015.

O’Gorman, J. P., R. A. Otero, N. Hiller, J. Simes, and M. Terezow. 2017. Redescription of Tuarangisaurus keyesi (Sauropterygia; Elasmosauridae), a key species from the Uppermost Cretaceous of the Weddellian province: internal skull anatomy and phylogenetic position. Cretaceous Research 71:118-136.

O'Keefe, R. F. 2001. A cladistic analysis and taxonomic revision of the Plesiosauria (Reptilia: Sauropterygia). Acta Zoologica Fennica 213:1-63.

O’Keefe, R. F. 2006. Morphologic and ontogenetic patterns in elasmosaur neck length, with comments on the taxonomic utility of neck length variables. Paludicola 5:207-229.

Otero, R. A., S. Soto-Acuña, F. R. O'Keefe, J. P. O’Gorman, W. Stinnesbeck, M. E. Suárez, D. Rubilar-Rogers, C. Salazar, and L. A. Quinzio-Sinn. 2014. Aristonectes quiriquinensis, sp. nov., a new highly derived elasmosaurid from the upper Maastrichtian of central Chile. Journal of Vertebrate Paleontology, 34:100-125.

Otero, R.A., J. P. O’Gorman, N. Hiller, F. R. O’Keefe, and R. E. Fordyce. 2016. Alexandronectes zealandiensis gen. et sp. nov., a new aristonectine plesiosaur from the lower Maastrichtian of New Zealand. Journal of Vertebrate Paleontology 36(2): e1054494.

Owen, R. 1860. On the orders of fossil and Recent Reptilia, and their distribution through time. Report of the British Association for the Advancement of Science 1859:153-166. 
Sachs, S. 2005. Redescription of Elasmosaurus platyurus Cope 1868 (Plesiosauria:

Elasmosauridae) from the Upper Cretaceous (lower Campanian) of Kansas, U. S. A. Paludicola 5:92-106.

Sachs, S., and B. P. Kear. 2015. Postcranium of the paradigm elasmosaurid plesiosaurian Libonectes morgani (Welles, 1949). Geological Magazine 152:694-710.

Sachs, S., J. Lindgren, and M. Siversson. 2015. A partial plesiosaurian braincase from the Upper Cretaceous of Sweden. Geological Society, London, Special Publications 434:293-301. Sato, T. 2002. Description of plesiosaurs (Reptilia: Sauropterygia) from the Bearpaw Formation (Campanian-Maastrichtian) and a phylogenetic analysis of the Elasmosauridae. Unpublished Ph.D. dissertation, University of Calgary, Alberta, Canada, 391 pp.

Sato, T. 2003. Terminonatator ponteixensis, a new elasmosaur (Reptilia: Sauropterygia) from the Upper Cretaceous of Saskatchewan. Journal of Vertebrate Paleontology 23:89-103.

Sato, T., Y. Hasegawa, and M. Manabe. 2006. A new elasmosaurid plesiosaur from the Upper Cretaceous of Fukushima, Japan. Palaeontology 49:467-484.

Sato, T., X. C. Wu, A. Tirabasso, and P. Bloskie. 2011. Braincase of a polycotylid plesiosaur (Reptilia: Sauropterygia) from the Upper Cretaceous of Manitoba, Canada. Journal of Vertebrate Paleontology 31:313-329.

Smith, A. S., and G. J. Dyke. 2008. The skull of the giant predatory pliosaur Rhomaleosaurus cramptoni: Implications for plesiosaur phylogenetics. Naturwissenschaften 95:975-980. Storrs, G. W., and M. A. Taylor. 1996. Cranial anatomy of a new plesiosaur genus from the lowermost Lias (Rhaetian/Hettangian) of Street, Somerset, England. Journal of Vertebrate Paleontology 16:403-420.

Stromer, E. 1935. Ergebnisse der Forschungsreisen Prof. E. Stromers in den Wusten Agyptens. Wirbeltierreste der Baharijestufe (unterstes Cenoman), 15. Plesiosauria: Abhandlungen der Bayerischen Akademie der Wissenschaften, Mathemetsch-naturwissenschaftliche 26:1-56. 
Taylor, M. A. 1992. Functional anatomy of the head of the large aquatic predator Rhomaleosaurus zetlandicus (Plesiosauria; Reptilia) from the Toarcian (Lower Jurassic) of Yorkshire, England. Philosophical Transactions of the Royal Society of London, Series B 335:247-280.

Underwood, C., K. M. Cleason, and D. J. Ward. 2009. Batoids from the Turonian of SE Morocco; pp. 43 in N. E. Jalil (ed.), 1st International Congress on North African Vertebrate Palaeontology, Program and Abstracts, Marrakech, 25-27 May 2009.

Vincent, P., N. Bardet, X. Pereda Suberbiola, B. Bouya, M. Amaghzaz, and S. Meslouh, 2011. Zarafasaura oceanis, a new elasmosaurid (Reptilia: Sauropterygia) from the Maastrichtian Phosphates of Morocco and the palaeobiogeography of latest Cretaceous plesiosaurs. Gondwana Research 19:1062-1073.

Vincent, P., N. Bardet, A. Houssaye, M. Amaghzaz, and S. Meslouh. 2013. New plesiosaur specimens from the Maastrichtian Phosphates of Morocco and their implications for the ecology of the latest Cretaceous marine apex predators. Gondwana Research 24:796-805.

Welles, S. P. 1943. Elasmosaurid plesiosaurs with a description of new material from California. Memoirs of the University of California 13:125-254.

Welles, S. P. 1949. A new elasmosaur from the Eagle Ford Shale of Texas. Fordren Science, Series $1: 1-28$.

Welles, S. P. 1952. A review of the North American Cretaceous elasmosaurs. University of California, Publications in Geological Sciences 29:47-144.

Welles, S. P. 1962. A new species of elasmosaur from the Aptian of Columbia and a review of the Cretaceous plesiosaurs. University of California Publications in Geological Sciences 44:1-96. Wiffen, J., and W. L. Moisley. 1986. Late Cretaceous reptiles (families Elasmosauridae and Pliosauridae) from the Mangahouga Stream, North Island, New Zealand. Journal of Geology and Geophysics, New Zealand 29:205-252. 
Williston, S.W. 1889. A New Plesiosaur from the Niobrara Cretaceous of Kansas. Transactions of the Annual Meetings of the Kansas Academy of Science 12:174-178.

Williston, S. W. 1903. North American plesiosaurs. Part I. Field Columbian Museum Publication $2: 1-79$.

Submitted September 08, 2016; accepted Month DD, YYYY
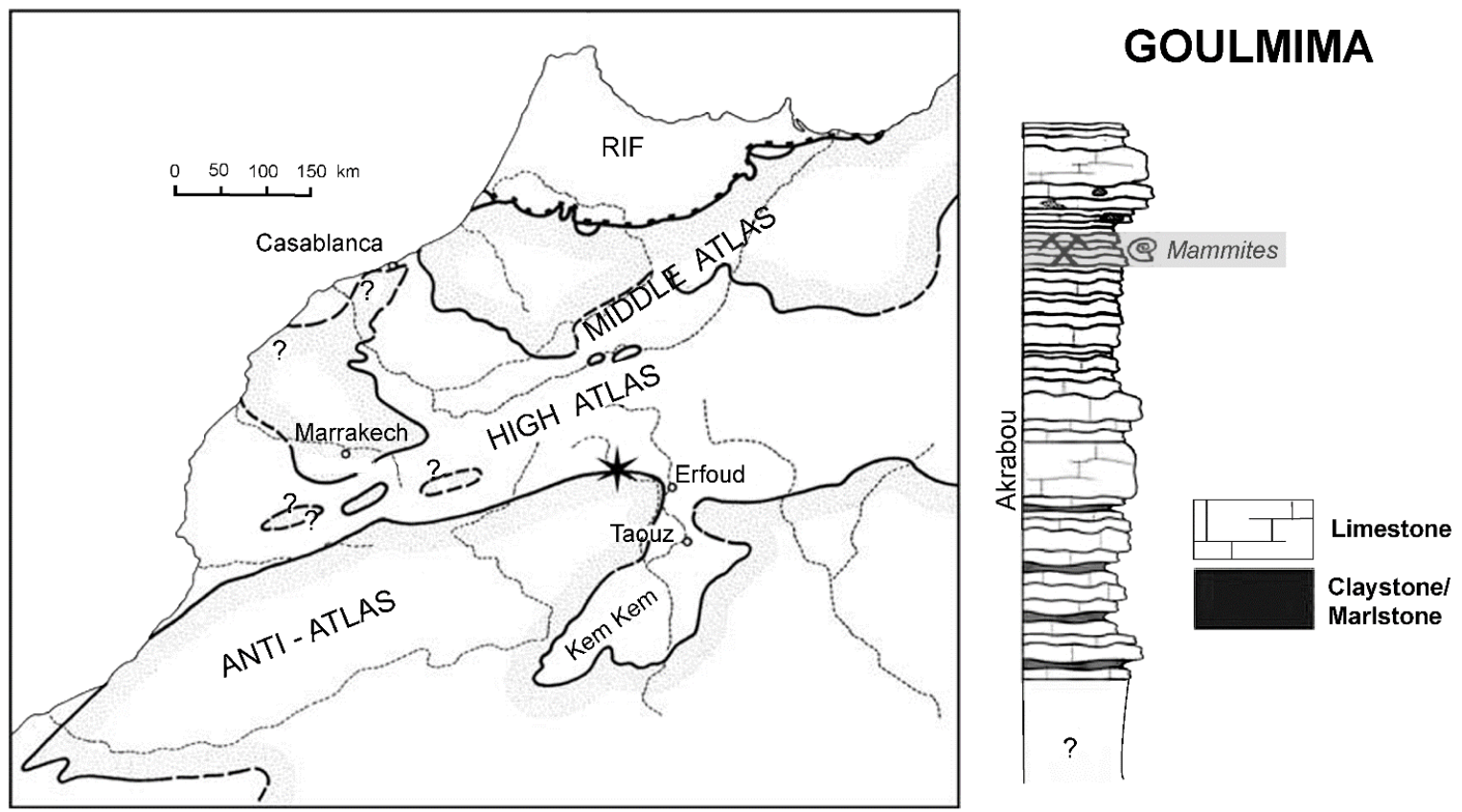

FIGURE 1. Palaeogeographical location of the Goulmima area in southern Morocco and probable stratigraphical range (Mammites horizon) of the plesiosaurian specimen SMNS 81783 (modified from Angst and Bardet, 2015). [planned for page width] 

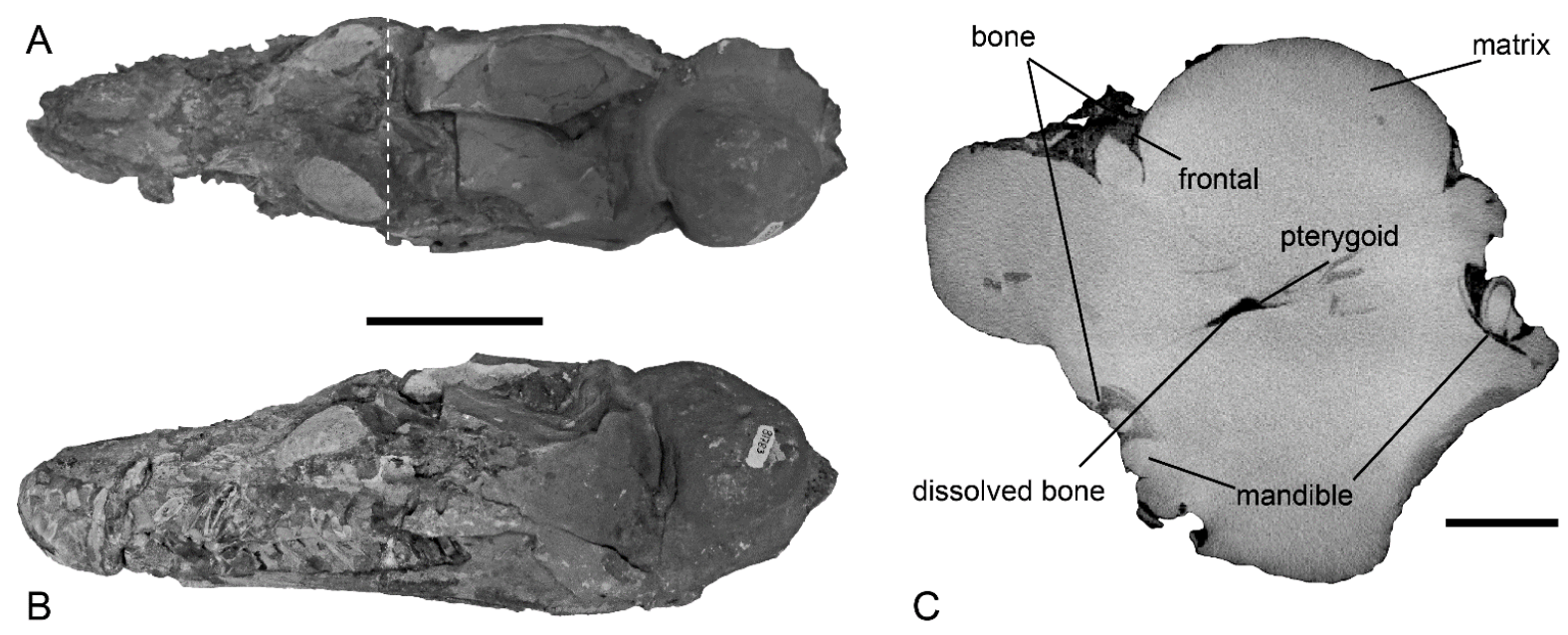

FIGURE 2. A, B. Photographs of SMNS 81783 in dorsal (A) and left lateral (B) views. The dotted line indicates the location of the transverse section. $\mathbf{C}$. Transverse section in the middle of the skull of SMNS 81783 showing the general state of preservation. Scale bars equal $10 \mathrm{~cm}$ (A, B) and $2 \mathrm{~cm}(\mathbf{C})$. [planned for page width] 

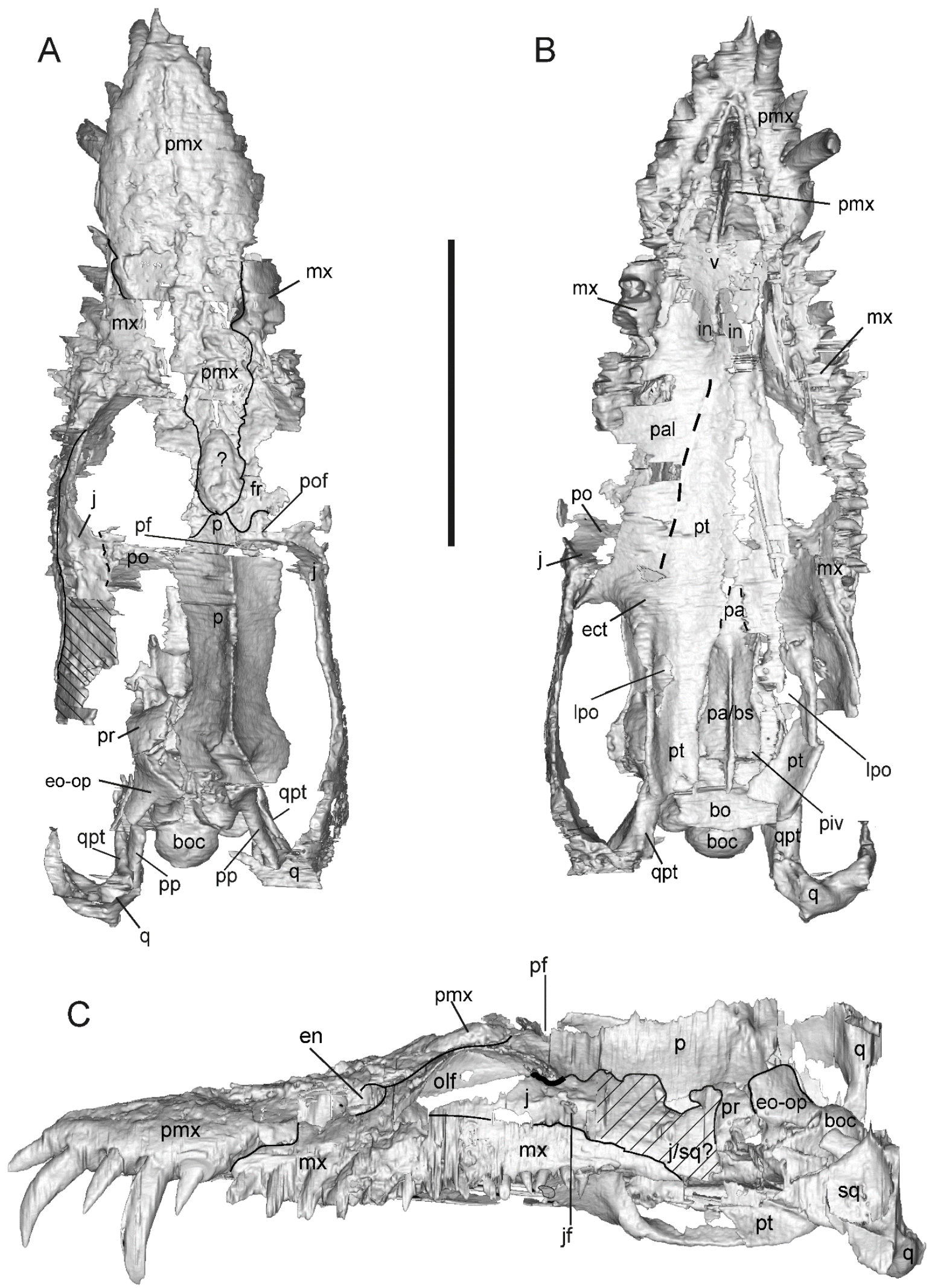
FIGURE 3. Digital reconstruction of the skull of SMNS 81783 in dorsal (A), ventral (B), and left lateral (C) views. Abbreviations: bo, basioccipital; boc, occipital condyle; ect, ectopterygoid; en, external naris; eo-op, exoccipital-opisthotic; fr, frontal; in, internal nares; j, jugal; jf, jugal foramen; lpo, lateral pterygoid opening; mx, maxilla; olf, lateral wall of the olfactory canal; p, parietal; pa, parasphenoid; pa/bs, parabasisphenoid; pal, palatine; pf, pineal foramen; piv, posterior interpterygoid vacuities; pmx, premaxillae; po, postorbital; pof, postfrontal; pp, paraoccipital process; pr, prootic; pt, pterygoid; q, quadrate; qpt, quadrate ramus of the pterygoid; sq, squamosal; v, vomer; ?, undetermined bone. Scale bar equals $10 \mathrm{~cm}$. [planned for page width]

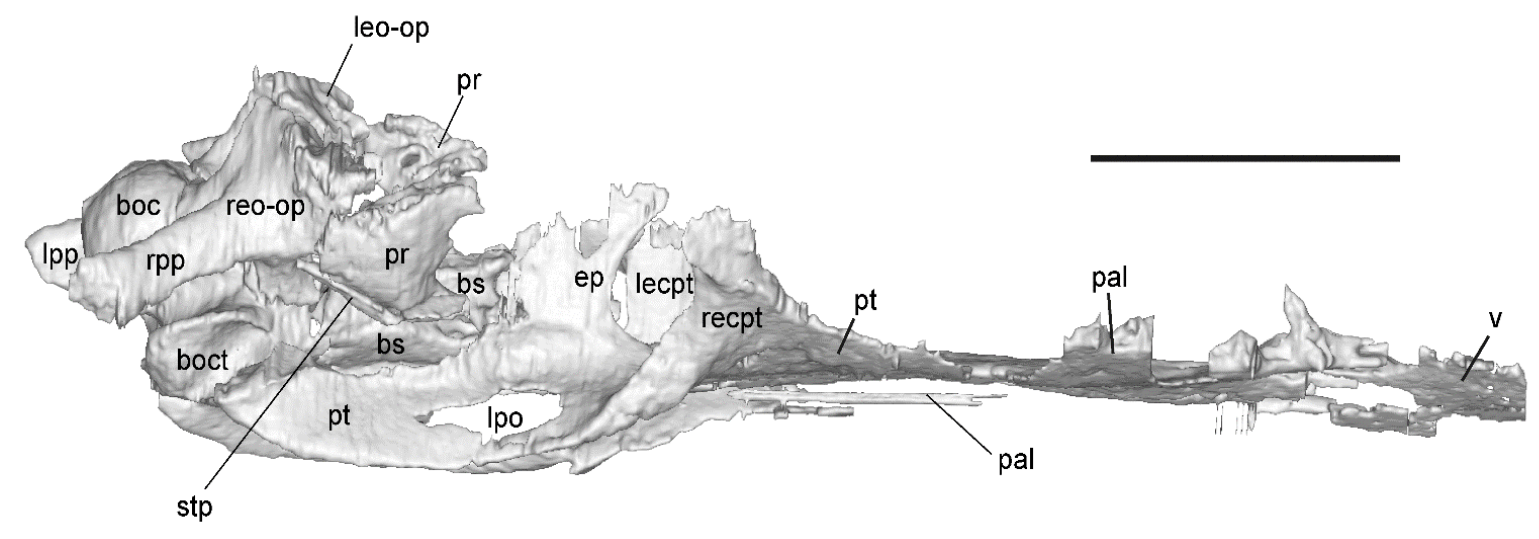

FIGURE 4. Digital reconstruction of the braincase and the palate of SMNS 81783 in right lateral view. Abbreviations: boct, basioccipital tuber; boc, occipital condyle; bs, basisphenoid; ep, epipterygoid; lecpt, left ectopterygoid; leo-op, left exoccipital-opisthotic; lpo, lateral pterygoid opening; lpp, left paraoccipital process; pal, palatine; pr, prootic; pt, pterygoid; recpt, right ectopterygoid; reo-op, right exoccipital-opisthotic; rpp, right paraoccipital process; $\mathbf{s t p}$, stapes; $\mathbf{v}$, vomer. Scale bar equals $5 \mathrm{~cm}$. [planned for page width] 

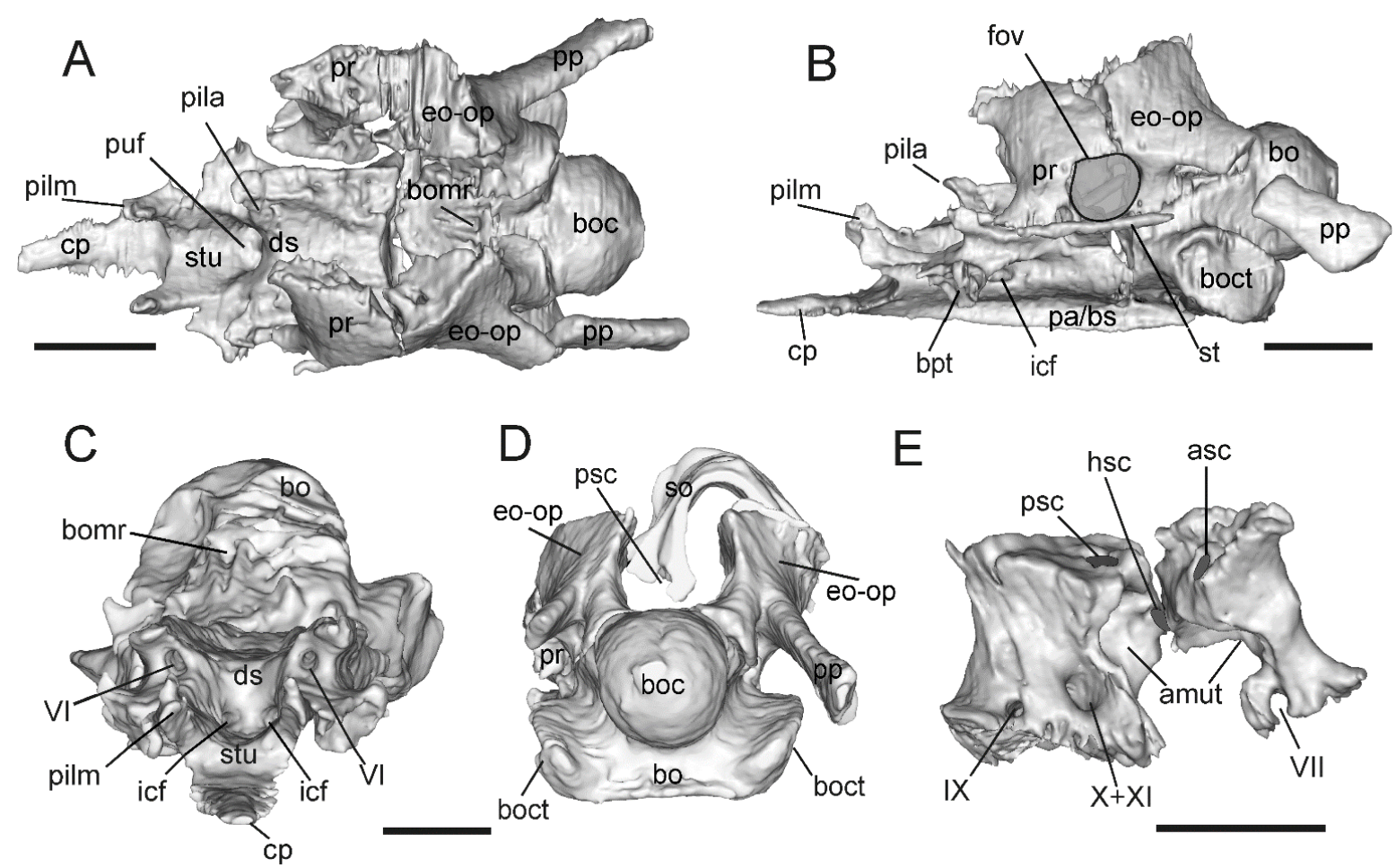

FIGURE 5. Digital reconstruction of the braincase of SMNS 81783 in dorsal (A), left lateral (B), anterior (C) and posterior (D) views and of the left exoccipital-opisthotic and prootic in medial view (E). Abbreviations: amut, chamber for ampulla and utriculus; asc, anterior semicircular canal; bo, basioccipital; boc, occipital condyle; boct, basioccipital tuber; bomr, basioccipital median ridge; bpt, basipterygoid process of the basisphenoid; cp, cultriform process; ds, dorsum sellae; eo-op, exoccipital-opisthotic; fov, fenestra ovalis; hsc, horizontal semicircular canal; icf, internal carotid foramen; IX, foramen for glossopharyngeal nerve; pa/bs, parabasisphenoid; pila, pila antotica; pilm, pila metoptica; pp, paraoccipital process; pr, prootic; psc, posterior semicircular canal; puf, pituitary fossa; so, supraoccipital; st, stapes; stu, sella turcica; VI, foramen for the abducens nerve; VII, foramen for the facial cranial nerve; $\mathbf{X}+\mathbf{X I}$, foramen for the vagus and accessory nerves. Scale bars equal $2 \mathrm{~cm}$. [planned for page width] 

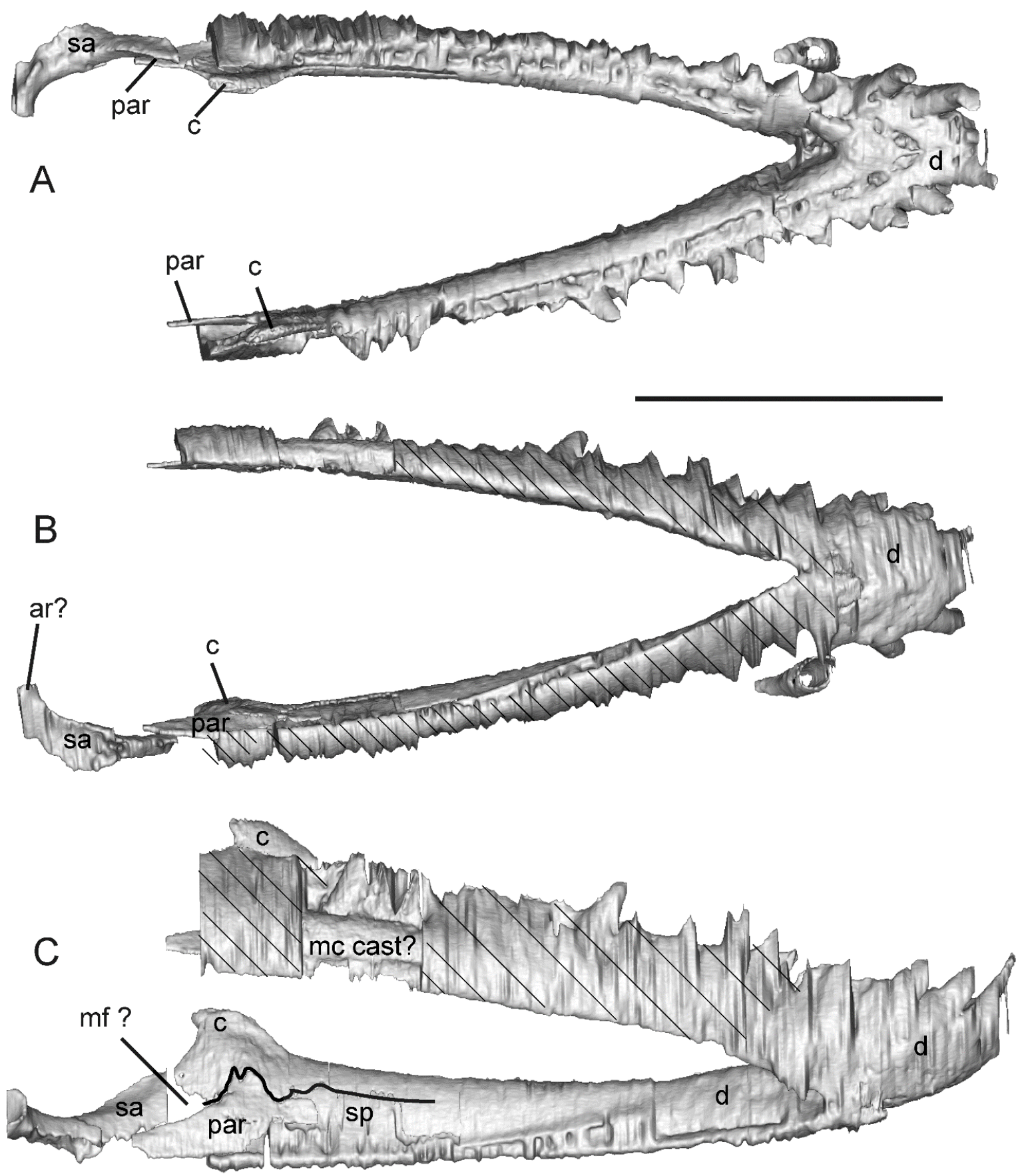

FIGURE 6. Digital reconstruction of the mandible of SMNS 81783 in dorsal (A), ventral (B) and right ventrolateral (C) views. Abbreviations: ar, articular; c, coronoid; d, dentary; mc cast, cast of the Meckelian canal; mf, mandibular foramen; par, prearticular; sa, surangular; sp, splenial. Scale bars equal $10 \mathrm{~cm}$. [planned for page width] 

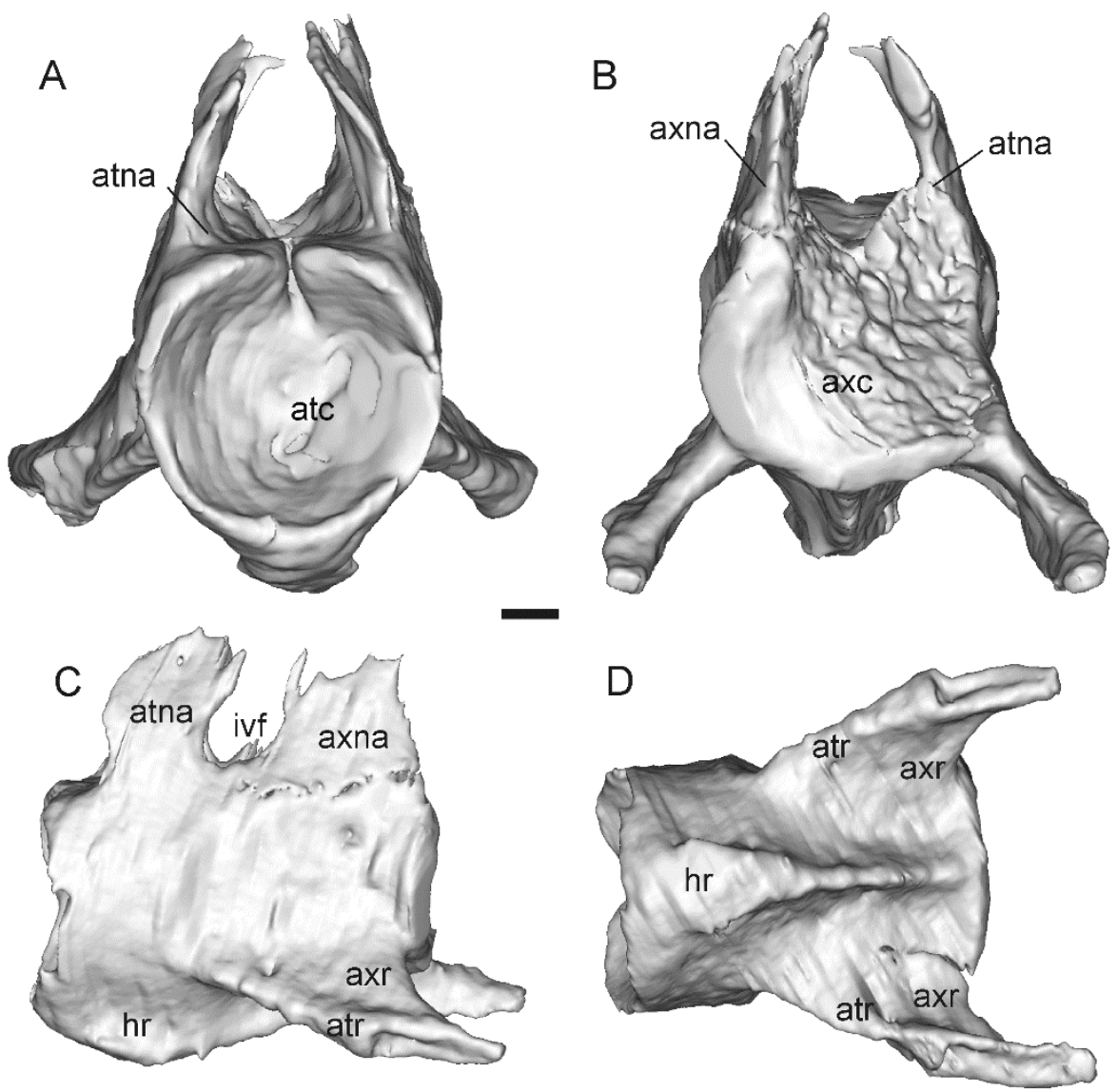

FIGURE 7. Digital reconstruction of the atlas-axis complex of SMNS 81783 in anterior (A), posterior (B), left lateral (C) and ventral (D) views. Abbreviations: atc, atlas centrum; atna, atlas neural arch; atr, atlas rib; axc, axis centrum, axna, axis neural arch; axr, axis rib; ivf, intervertebral foramen; hr, hypophyseal ridge. Scale bar equals $1 \mathrm{~cm}$. [planned for $2 / 3$ page width] 


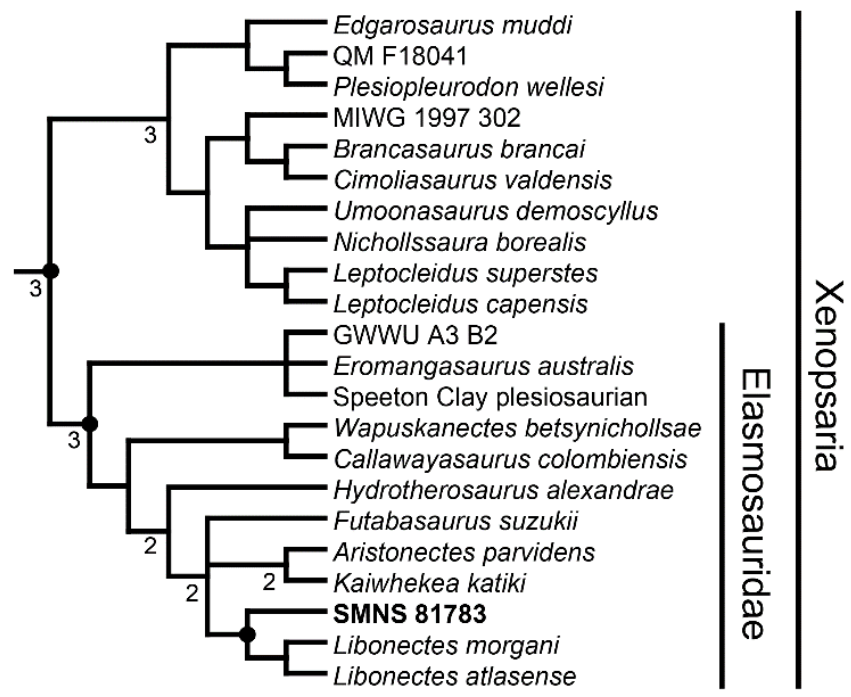

FIGURE 8. Strict consensus tree showing the relationships of the specimen SMNS 81783

among xenopsarians. Strict consensus of the 100 most parsimonious trees; tree length $=1345$

steps; $\mathrm{CI}=0.24 ; \mathrm{RI}=0.62$. Bremer indices higher than one are indicated for each node.

[planned for column width] 